\title{
Discussion on the distribution live work and the protection
}

\author{
Zhan Hengfu, Wu Yufeng, Feng Haijiao \\ Benxi Power Supply Company of National Grid Liaoning Electric Power Co., Ltd. \\ bxwl_650928@126.com
}

Keywords: distribution; live work; protection

\begin{abstract}
With the rapid development of China's social economy, the demand for power is increasing, and the construction of the power distribution network is valued by the power supply units. In the power distribution network, live work has a certain risk, so the operational team of high level should be built, the economical efficiency and reliability of the operation of the power system, and the operation safety of the operators and the equipment should be improved, so as to improve the safety of the operation mode. This paper analyzes the operation requirements and tools of live work, providing experiences for the future development of the power industry.
\end{abstract}

\section{Introduction}

In the 1960s to 1980s, China promoted the live work, but it had a lot of problems in the safety protection, operation procedures, protective equipment and operation mode, which would endanger the safety of construction operators, and reduce the reliability and safety of the operation.

Reliability of electric power supply has become an important task, and the live work of distribution repair and maintenance of power supply enterprises ensures the reliability of power supply, as so to improve the work efficiency of the field, meanwhile it is the necessary maintenance measure for power supply enterprises to get more economic and social benefits in the electricity market. The ultimate goal of the live work is to avoid power outage maintenance, to rule out fault while ensuring the normal power supply.

Human body is charged, that is, human body has safe voltage and current. The electric field on the surface of human skin is generally $240 \mathrm{kV} / \mathrm{m}$. Once a scientific research department did such experiments where a person stood on the ground, and the maximum electric field intensity at the top of the head is over 10 times of the field intensity around. When a normal person is in the uniform electric field of $10 \mathrm{kV} / \mathrm{m}$, the electric field at the highest point of his head actually reaches the highest value in theory, which is still less than the electric field inductive data of human skin. For this reason, the international electric safety regulations generally believes the electric field intensity of high voltage transmission line less than $10 \mathrm{kV} / \mathrm{m}$ is safe, and some countries also provide the provisions of no more than $5 \mathrm{kV} / \mathrm{m}$ or below. There is no limit in working time, and once the area is over $20 \mathrm{kV} / \mathrm{m}$, it is necessary to take protective measures. This also shows that the human body can withstand a certain voltage, and carry out live work under the safe field in the maintenance.

\section{Operation mode of distribution live work}

Live work can be divided into the following types based on the tools used or insulation modes.

By insulation modes.

According to the different insulation modes, the live work is divided into two kinds of direct and indirect operations. The direct operation refers to the operators, wearing protective appliance, closes to the charged body through the insulation ladder and other tools. The indirect operation refers to taking the insulation tool as the main insulation, and the wearing appliances as auxiliary insulation. The distribution live work, whether by a direct mode or an indirect mode, belongs to the intermediate potential operation mode, if it is divided according to the human body potential of the operators. 


\section{By the insulation tools used.}

According to the different insulation tools, the operation mode is divided into the following types. First, it is the operation mode of insulation tools. The operators climb up the pole to the appropriate position by using irons and other devices, buckle the safety belt, keep a certain distance to the system voltage and work through the insulating pole. The operation mode above has the following characteristics. It is less affected by such factors as terrain and traffic and the construction can be done where the pole cannot reach. Second, it is the platform operation mode. The insulation platform is composed of the insulation car, herringbone ladder and striga ladder, and operators carry out operation by using insulation tools or insulation gloves. Insulation platform plays the role of the main insulation. Whether by indirect or direct methods, before the maintenance phase, the adjacent charged bodies normally should be shielded or isolated by insulation protective and isolated equipment. At the same time, the operators should wear a full set of insulation protective equipment. When they work directly by using the insulation gloves, rubber insulation gloves should be covered by the protective gloves to avoid wearing out or thrusting. Third, it is the operation mode of insulated boom type aerial. As early as in the 1930s, the above equipment has been used in the western countries, and in the late 50s, it has been widely used in the process of live work. Its advantages lie in a larger range of application, flexibility, construction convenience, and higher labor efficiency.

\section{The characteristics of live work of distribution network}

In the process of live work, the high voltage is relatively low, the equipment is intensive, the operation space, the wire distance of distribution network and the action range is small and it is easy to touch the potential, so the operators should not use the equal potential operation mode, and the main reasons are as follows. First, it may result in the interphase short circuit. When the charged body is not covered or not covered completely and the operators are repairing the cables wearing the shielding clothing, they may contact the two-phase charged bodies at the same time and result in short circuit if the action range is large. If the current is large, it will not only get through the shielding clothing and result in short-circuit, but also even lead to the operators' death. Second, it may cause a relatively short circuit. When the operators replace insulator and cross arm in line tower and wear a full set of shielding clothing, different parts of their body may also contact the charged body and grounding body and a single-phase ground is formed. Although the $6 \sim 10 \mathrm{kV}$ system is in the way of a neutral un-grounding, if the line is relatively long or connected with a certain length of cable, the current of three-phase capacitor will exceed the discharge current capacity of the shielding clothing as well, causing casualties. During live work, the operators should not wear shielding clothes, but wear insulation appliances, and do the work by the combination of main insulation and auxiliary insulation.

\section{Safety protection equipment of distribution live work}

\section{Insulation cover.}

An insulation cover is the protective shield used to cover the charged conductor or a non charged conductor. In the charged appliances, the cover does not play a role of the main insulation, and it only plays the protective role of insulation shielding or isolation when the charged operators touch the charged body for a short time. When the insulation cover is used in live work, there should be enough safety and reliability, so before its usage, it must be strictly checked through electrical, mechanical and other tests. The voltage requirements of power frequency test of the cover are shown in Table 1.

\section{Insulation clothing.}

When operators wearing a full set of insulation clothing to do live work, generally two kinds of operation modes are used: One is wearing a full set of insulation clothing and contacting with the charged body through insulating gloves directly, which is welcomed by foreign construction operators. The insulation clothing can realize insulation between the charged body and human body, 
the problem such as the relatively small clearance distance can be effectively solved, but taking into account of the small safety margin of the insulation protectors and the possible wear, therefore, in direct operations it is only taken as auxiliary insulation but not the main insulation. The other is indirect work through insulation tools, where the insulation tools are taken as main insulation, while insulation protective clothing and insulation gloves are the backup appliances of personal safety.

\section{Steps and safety precautions for distribution live work}

\section{Preparation and safety attentions before live work.}

(1) Preparation of the tools and materials to be taken to the field. 1)Before the work, according to the requirements of field operations and project work, enough insulation shielding equipment and protective equipment should be ready; 2) The insulation shielding equipment, protective equipment and tools to be taken to the field must be counted and checked to make sure its intactness and enough quantity, and respectively put in the specified tool bags.

(2) Implementation of the programme. For the routine simple work projects, the team leader should make a work plan in the day of the implementation of the live work in the field, and for the more complex work projects, the team leader should do investigation and research and make the plan before the work.

(3) Loading. When tools and materials are loaded, they should be classified, to prevent the collision, scratching or puncture of the insulation shielding equipment and protective equipment.

(4) Discharge. 1) the insulation shielding equipment, the protective equipment and the insulation pole of live work shall be placed on the moisture proof plastic in the dry and cool place to prevent the striking from other objects. 2) the place which does not affect the work shall be selected and they are placed and classified by the material, tools, insulation cover, and protective equipment;

(5) Work description, labor division and the former meeting. 1) the team leader should propose the work instruction before the work, give a detailed explanation of the work content, work sequence, labor division and attentions in the meeting before the work, and make clear of the labor division of each operation.:

(6) The preparatory work before the pole climbing: 1) insulation gloves and protective gloves shall be carried in a particular bag; 2) before the pole climbing, the operators should put on the insulation clothing, insulation boots and the safety helmet on the ground; 3 ) the safety belt and the auxiliary cable should be convenient in use and correctly carried.

(7) The inspection of tools, insulation shielding equipment, and protective equipment. 1) high voltage insulation gloves and insulation boots should be filled by air to check whether there is the defects as pinhole; 2) whether the screws of tools is loose in handling should be checked, and whether insulation shielding equipment and protective equipment has cracks, crushing, damage or other damage.

\section{Conclusion}

In the distribution live work, it is not suitable to use equal potential operation mode, and it should improve the insulation level, service performance and moisture level of protective equipment to improve the safety and the convenience of the operators in the work. In order to improve the safety level of operators, they should wear a full set of protective equipment in the process of live work, and take the use of the way of combining main insulation and auxiliary insulation.

\section{Reference}

[1] Zhao Wei, Yang Mei, Liu Hongbin, Wu Wei, Research and development of GIS based on component. Computer and modernization 2005. 06 
[2] Wang Ninghui Practical manual of electrical engineer (power supply), Beijing: Machinery Industry Press, 2006

[3] Hu Jianxun, Liu Kai, Liu Ting, et al. Study on the live work test of 500kv high altitude compact transmission [J]. High voltage apparatus, 2010, 46 (4):35.39.

[4] Zhang Jin, Ji Shengchang, Shen Qi, et al. Study on $35 \mathrm{kV}$ insulator string flashover voltage washed by charged water vapor[J]. High voltage apparatus, 2010, 46 (7):61.65.

[5]IEEE Committee Report. Recommendations for safety in live line maintenance[J].IEEE Transactions on Power Apparatus and Systems,1968,87(2):346—352.

[6]State Grid Corporation of China.The power supply enterprise safety risk assessment standard[M]. Beijing:China Electric Power Press,2009. 